\title{
Assessment of Job Satisfaction Level and Its Associated Factors among Health Workers in Addis Ababa Health Centers: A Cross-Sectional Study
}

\author{
Mesfin Aklilu (D), ${ }^{1}$ Waleleng Warku, ${ }^{2}$ Wogayehu Tadele, ${ }^{1}$ Yimer Mulugeta, \\ Hussene Usman, ${ }^{3}$ Amelework Alemu, ${ }^{1}$ Sintayehu Abdela, ${ }^{1}$ Alemnesh Hailemariam, \\ and Endalkachew Birhanu' \\ ${ }^{1}$ Ethiopian Public Health Institute, P.O. Box 1242, Addis Ababa, Ethiopia \\ ${ }^{2}$ University of Gondar, Institute of Public Health, P.O. Box 196, Gondar, Ethiopia \\ ${ }^{3}$ Oromia Health Bureau, Addis Ababa, Ethiopia \\ Correspondence should be addressed to Mesfin Aklilu; mesfinaklilu@yahoo.com
}

Received 1 January 2020; Revised 22 July 2020; Accepted 25 July 2020; Published 30 September 2020

Academic Editor: Giuseppe La Torre

Copyright ( 2020 Mesfin Aklilu et al. This is an open access article distributed under the Creative Commons Attribution License, which permits unrestricted use, distribution, and reproduction in any medium, provided the original work is properly cited.

\begin{abstract}
Health workers account for the largest share of public expenditures on health and play an important role in improving the quality of health services. There is concern that poor health worker performance limits the effectiveness of health systems strengthening efforts. A cross-sectional study was conducted from September to October 2016 in Addis Ababa health centers. Data were collected from 420 healthcare workers using a pretested and structured questionnaire by trained data collectors. EPI Info 7 was used for data entry, and analysis was done by SPSS version 20. Bivariate and multivariate logistic analyses were used to identify factors associated with the outcome variable and to control confounders. $P$ values less than 0.05 were considered statistically significant. The overall job satisfaction level accounts for 53.8\% with 95\% CI of (48.9\%, 59.0\%). Marital status and professional qualification were the potent predictors of job satisfaction. Respondents who never married were 1.65 times more likely to be satisfied in their job than those married or divorced (AOR: 1.65 (95\% CI: 1.02, 2.66)). Laboratory professionals and nursing professionals were 2.74 and 1.97 times more likely to be satisfied in their job compared to health officers (AOR: 2.47 (95\% CI: 1.14, 6.59) and AOR: 1.97 (95\% CI: 1.12, 3.48), respectively). More than half of the healthcare workers in the study area were satisfied in their job. Marital status and healthcare workers' profession type were predictors of job satisfaction. Research studies indicate that there is a positive relationship between performance and job satisfaction. Accordingly, the present study aimed at determining the level of job satisfaction of health workers and its associated factors in the health centers of Addis Ababa, Ethiopia.
\end{abstract}

\section{Introduction}

Health workers account for the largest share of public expenditures on health and play a crucial role in efforts to improve the availability and quality of health services [1]. Job satisfaction of employees is one of the most challenging concepts in any organization and is the basis for many of the policies and management strategies to increase productivity and efficiency [2]. In Ethiopia, the overall performance of health workers is negatively impacted by low levels of health worker motivation and job satisfaction [1].
Job satisfaction of employees is one of the most challenging concepts in any organization and is the basis for many of the policies and management strategies to increase productivity and efficiency. It is influenced by many factors including environmental and personal factors, income, nature and social status of the job, organizational prestige, promotion, job security, lack of role, ambiguity, and physical job conditions of coworkers such as lighting, noise, and space that affect people's ability to work [2].

The overall job satisfaction of health workers recorded in Jimma University Specialized Hospital was 41.4\% [3]. The 
dissatisfaction level of nurses in public health facilities of Ethiopia showed $47 \%$ too [4]. Research studies in job satisfaction level in Ethiopia recorded up to $67 \%$ in nurses [5] and $62 \%$ in midwives [6], while in general healthcare workers in public health facilities indicated $41 \%$ to $44.5 \%$ [7-9].

Research consistently demonstrates a relationship between core job characteristics and job satisfaction. Along with higher job satisfaction and motivation, employees performing enriched jobs usually experience lower absenteeism and turnover [10]. Job characteristics have an influence on critical psychological states, which in turn influence personal and work outcomes, given the strength of the employee's growth needs. Positive psychological states are associated with high internal work motivation, highquality work performance, high satisfaction with the work, and low absenteeism and turnover [11]. The core job characteristics significantly predict and influence the three psychological states, and such psychological states significantly influence civil servants' internal motivation, general job satisfaction, and their performances [12]. The study conducted in Nigeria revealed a significant positive strong correlation between the overall work environment and the general job satisfaction of the nurses [13].

Research studies showed that leaders' behavior impact the subordinates such that they are motivated to achieve both organizational goals and their individual-valued goals [14]. The main factors that correlated with healthcare workers' overall job satisfaction were conflict resolution at work, support from one's supervisor, and relationship with coworkers [15]. In Kenya, job satisfaction is an indicator for the recruitment and retention of healthcare staff and the provision of good quality of care [16].

Research studies indicated that marital status, sex, and tenure of service [17], professional background [3], and male employees [18] have significant associations for job satisfaction. In Ethiopia, research studies showed that salary $[7,9]$, the profession of healthcare workers $[5,6,8]$, marital status [5], and sex of healthcare workers [6] were significant predictors of job satisfaction.

Despite the fact that various studies conducted among health workers in different health institutions of the country magnify the severity of the problem, most papers focus on a specific profession and academic institutions. The aim of this study was to determine the level of job satisfaction of health workers and the associated factors in the health centers of Addis Ababa, Ethiopia.

\section{Methods}

An institution-based cross-sectional study was conducted in twenty-four health centers from four subcities in Addis Ababa. Primary data were collected using a structured and pretested questionnaire. A total of 376 healthcare workers participated in the study. Based on the fact that the Ethiopian health policy focuses on midlevel health professionals, participants selected randomly from 24 health centers of the capital Addis Ababa were 6 (1.6\%) diploma holder health assistants, 23 (6.1\%) diploma holder pharmacists, 28 (7.4\%) first degree holder laboratory technicians, 104 (27.7\%) first degree holder health officers, 89 (23.7\%) BSc degree holder nurses, 7 (1.9\%) diploma holder laboratory technicians, 82 (21.8\%) diploma holder nurses, and 35 (9.3\%) degree holder pharmacists. There are ten subcity health offices under Addis Ababa Health Bureau. Four subcity health offices (Bole, Kirkos, Yeka, and Gullele) were selected randomly as a sampling frame. Randomly selected health centers, six from each subcity, were the study areas. Simple random sampling methods were used to select participants at each stage of sampling. Data were collected from six health centers from September to October 2016. The overall job satisfaction level of respondents was determined using a mean score for each factor. Accordingly, the score above the mean was taken as being satisfied for each factor while the score below the mean was classified as being dissatisfied. The study was conducted after the ethical approval of Addis Continental Institute of Public Health Institutional Review Board. Data were collected after written consent with a brief description of the importance of the study to the participants. The collected data were checked for completeness, accuracy, and consistency. Cleaned and coded data were entered with Epi Info version 3.5.3 software (Atlanta, Georgia) by an experienced data clerk with close supervision and support. Cleaned and edited data were analyzed using Statistical Software for Social Sciences (SPSS) version 20. Descriptive and inferential statistical analyses were employed. Bivariate and multivariate logistic regression models were also used to detect the potential predictors of job satisfaction. Factor variables having a $P$ value of 0.25 and less in the bivariate analysis were included in the multivariate analysis. For the relationship of job satisfaction of health workers and predictor variable, $P$ values less than 0.05 were considered statistically significant.

Ethical approval was obtained from Addis Ababa Health Bureau and Addis Continental Institute of Public Health Institutional Ethics Review Board. Consent was obtained from each participant and confidentiality was assured before data collection.

\section{Results}

The mean age of the participants was $29.9 \pm 5.8 \mathrm{SD}$ (standard deviation). The age of the participants ranges from 23 to 53 . The median age was 28 with an interquartile range of 5 (26 and 31) years. The minimum and maximum years of experience were 1 and 34 years, respectively. The median year of experience was 5 years and the interquartile range of participants' year of experience was 5 (3 and 8 years). The majority $(73.2 \%)$ of the respondents belonged to the age groups less than and equal to 30 years. Almost half of the respondents were married (Table 1 ).

The overall level of job satisfaction was $53.8 \%$ with $95 \%$ CI of $(48.9 \%, 59.0 \%)$ (Figure 1). The respondents were satisfied with helping others (88.5\%), task significance $(81.1 \%)$, task identity $(74.3 \%)$, and feedback (74. 5\%). The major dissatisfaction factors were income $(6.83 \%)$, professional hazard (27\%), availability of resources and supplies (27\%), and workload (32.2\%). 
TABle 1: The sociodemographic characteristics of study participants in selected Addis Ababa health centers, 2016.

\begin{tabular}{|c|c|c|c|}
\hline Background characteristics & & $n$ & $\%$ \\
\hline \multirow{2}{*}{ Gender } & Male & 157 & 41.4 \\
\hline & Female & 222 & 58.6 \\
\hline \multirow{3}{*}{ Marital status } & Never married & 181 & 48.3 \\
\hline & Married & 190 & 50.7 \\
\hline & Divorced & 4 & 1.1 \\
\hline \multirow{3}{*}{ Educational status } & Diploma & 111 & 30.1 \\
\hline & BSc degree & 254 & 68.8 \\
\hline & Master's degree & 4 & 1.1 \\
\hline \multirow{3}{*}{ Age group } & $\leq 30$ & 278 & 73.2 \\
\hline & $31-40$ & 75 & 19.7 \\
\hline & $\geq 41$ & 27 & 7.1 \\
\hline \multirow{4}{*}{ Years of experience } & $\leq 1$ & 45 & 11.8 \\
\hline & $2-5$ & 167 & 43.9 \\
\hline & $6-10$ & 111 & 29.2 \\
\hline & $>10$ & 57 & 15.0 \\
\hline \multirow{3}{*}{ Income level in birr } & $\leq 2000$ & 97 & 25.5 \\
\hline & $2001-4000$ & 149 & 39.2 \\
\hline & $>4000$ & 134 & 35.3 \\
\hline \multirow{9}{*}{ Professional qualification } & Health assistant & 6 & 1.6 \\
\hline & Pharmacy diploma & 23 & 6.1 \\
\hline & Lab tech degree & 28 & 7.4 \\
\hline & Health officer & 104 & 27.7 \\
\hline & BSc nurse & 89 & 23.7 \\
\hline & Lab diploma & 7 & 1.9 \\
\hline & Diploma nurse & 82 & 21.8 \\
\hline & Pharmacist & 35 & 9.3 \\
\hline & Others & 2 & .5 \\
\hline
\end{tabular}

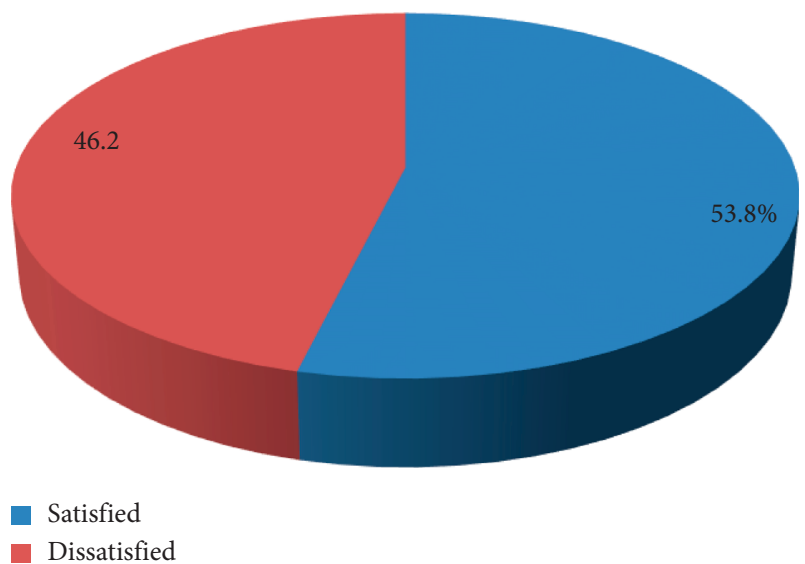

FIGURE 1: Overall level of job satisfaction.

The study revealed 206 health professionals satisfied and 166 dissatisfied in their job (Figure 2).

Further analysis was performed using the crude odds ratios (CORs) with 95\% confidence in bivariate analyses and adjusted odds ratios (AORs) with 95\% confidence intervals which were obtained from the multivariate logistic regression model. In the model, variables which specify the respondents' level of satisfaction to the job were considered as outcome variables whereas gender, age group, marital status, level of education, professional qualification, and income level were categorized as explanatory variables.
In the multivariate logistic regression model, marital status and professional qualification were the potent predictors of job satisfaction. Those respondents who married were 1.65 times more likely to be satisfied in their job (AOR: 1.65 (95\% CI: 1.02, 2.66)) than those who were not married or divorced. Laboratory professionals and nurse professionals were 2.74 times (AOR: 2.74 (95\% CI: 1.14, 6.59)) and 1.97 times (AOR: 1.97 (95\% CI: 1.12, 3.48)), respectively, more likely to be satisfied in their job compared to health officers (Table 2).

\section{Discussion}

The overall level of job satisfaction from the total participants of health workers in Addis Ababa health centers was $53.8 \%$ for those who were satisfied and $46.2 \%$ for those who were dissatisfied in their job. Marital status and professional qualification were found to be the potent predictors of job satisfaction. The major subscales which contributed most to the overall job satisfaction were helping others (88.5\%), task significance $(81.1 \%)$, task identity $(74.3 \%)$, and feedback (74.5\%). The study incorporated the five core job characteristics of Hackman and Oldham's job characteristics model into the tool [19]. This is very important as policymakers can get inputs from the result while designing strategies to improve healthcare workers' satisfaction and increase the retention rate of health workers in different governmental healthcare facilities. 


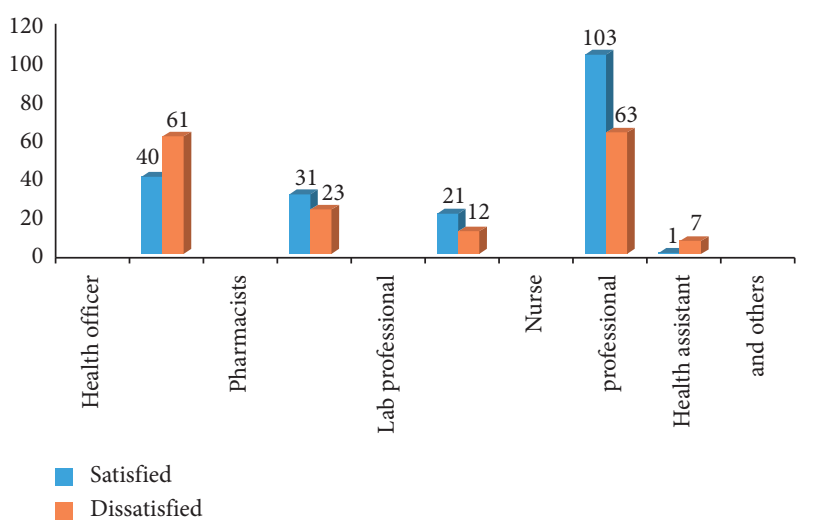

FIgURE 2: Satisfaction level of health professionals in terms of discipline.

TABLE 2: Bivariate and multivariate analyses of demographic factors associated with job satisfaction of health workers in Addis Ababa health centers, December 2016.

\begin{tabular}{|c|c|c|c|c|c|}
\hline \multirow{2}{*}{ Background characteristics } & & \multicolumn{2}{|c|}{ Level of satisfaction } & \multirow{2}{*}{ COR 95\% CI } & \multirow{2}{*}{ AOR 95\% CI } \\
\hline & & Satisfied & Dissatisfied & & \\
\hline \multirow{2}{*}{ Marital status } & Never married & 106 & 67 & $1.76(1.16,2.67)^{*}$ & $1.65(1.02,2.66)^{* *}$ \\
\hline & Married/divorced & 89 & 99 & 1 & 1 \\
\hline \multirow{3}{*}{ Educational status } & Diploma & 70 & 34 & 1 & 1 \\
\hline & BSc degree and above & 125 & 126 & $2.08(1.28,3.35)^{*}$ & $0.89(0.38,2.04)$ \\
\hline & $\leq 2000$ & 63 & 29 & 1 & 1 \\
\hline \multirow[t]{4}{*}{ Income level in birr } & $2001-4000$ & 74 & 70 & $2.53(1.45,4.435)^{*}$ & $0.51(0.22,1.21)$ \\
\hline & $>4000$ & 60 & 70 & $1.23(0.77,1.98)$ & $0.49(0.18,1.33)$ \\
\hline & Health officer & 40 & 61 & 1 & \\
\hline & Pharmacy professional & 31 & 23 & $2.05(1.05,4.02)^{*}$ & $1.85(0.87,3.93)$ \\
\hline \multirow[t]{3}{*}{ Professional qualification } & Lab professional & 21 & 12 & $2.67(1.18,6.02)^{*}$ & $2.74(1.14,6.59)^{* *}$ \\
\hline & Nurse professional & 103 & 63 & $2.49(1,50,4.14)^{*}$ & $1.97(1.12,3.48)^{* *}$ \\
\hline & Health assistant and others & 1 & 7 & $0.22(0.026,1.83)$ & $0.13(0.01,1.22)$ \\
\hline
\end{tabular}

The overall satisfaction level of the present study (53.8\%) was not consistent with the previous studies done in Jimma Specialized Hospital (41.4\%) [4], whereas consistent with nurses working in Sidama Zone Public Health Facilities (52.5\%) [3]. A similar finding on midwifery showed that $52.9 \%$ of workers were satisfied in their job [6]. Similar findings were also observed in Malaysia in fast food outlet managers. The corelational study conducted to examine the contribution of Hackman and Oldham's core job characteristic theory which states that when a job has a high score on the five core characteristics, it is likely to generate three psychological states, which can lead to positive work outcomes, such as high internal work motivation, high satisfaction with the work, high quality work performance, and low absenteeism and turnover [19]. The result was also in line with the study conducted in Nigeria that the relationship between core job characteristics and job satisfaction influences the overall satisfaction of employees on core job dimensions [12].

The job satisfaction level of the present study was high compared to a study done in Pakistan in that $86 \%$ [20] of nurses were dissatisfied in their job. The major reason for dissatisfaction in this study was income (6.83\%). Income has always been reported to be the usual predictor of job satisfaction of health workers [21]. It revealed that only $5.7 \%$ of nurses were satisfied in terms of basic salary. Other factors that contributed to dissatisfaction of health workers were professional hazard (27\%), availability of resources and supplies (27\%), workload (32.2\%), and physical working place conditions $(39.1 \%)$. Thus, these factors may be the reason for job satisfaction difference in health facilities.

Marital status and professional qualification were the potent predictors of job satisfaction. The finding was consistent with the study done in England in that married employees were less satisfied with their job than the single ones pertaining to a relationship between different factors and job satisfaction [22]. This finding is supported by other similar studies in Ethiopia in which marital status and type of profession were the predictors of job satisfaction [6, 7].

A similar study done among nonacademic staff in the universities of Sri Lanka showed that job satisfaction of unmarried staff was higher than that of the married staff [18]. However, the result was not consistent with several studies conducted inside and outside the country [8, 23]. In these studies, singles reported a higher level of job stress and a lower level of job satisfaction than their married counterparts [3]. This is justified by the support from the spouse which may lower the job tension after the day's work which may not be available to single workers [4]. 
In the study, laboratory professionals and nurses were more likely to be satisfied in their job than health officers. This professional category difference was also observed in different research studies $[5,8,23]$. This professional variation may be a difference in salary and professional type that leads to job satisfaction status $[6,9,24]$. The paper is not free from limitations; analysis was conducted using changed to Likert scale into binary mean scale, this may collapse the responses from five scales into two, while we used multivariable logistic regression that clearly indicates the predictor variables, marital status, and type of health professions.

\section{Conclusion}

The study indicated that there is a low level of job satisfaction in Addis Ababa health offices which can greatly affect the quality of health services provided. Marital status and type of professions were predictors for the job satisfaction level of healthcare workers. It entails further investigation to justify the controversial finding of the present study which explained singles were more satisfied than married unlike other studies in a similar setting.

\section{Recommendations}

Among the major subscales in the present study, three factors that are adopted from the job characteristics model besides helping others contributed most to the overall job satisfaction score:

(1) Skill variety: the degree to which a job requires a variety of different activities in carrying out the work, which involved the use of a number of skills and talents of the employee

(2) Task identity: encourage the feeling that the job is meaningful and worthwhile, thus motivating the employee to work smart

(3) Feedback: the degree to which carrying out the work activities required by the job results in the employee obtaining information about the effectiveness of his or her performance

Motivation can be enhanced by making the job so interesting and the worker so responsible that he or she is motivated simply by performing the job. Specifically, enriching jobs with skill variety, task identity, and feedback gives employees tasks requiring higher levels of skill and responsibility and greater control over how to perform their jobs.

\section{Data Availability}

The data used to support the findings of the study are available from the corresponding author at any time on request through mesfinaklilu@yahoo.com.

\section{Conflicts of Interest}

The authors declare that they have no conflicts of interest.

\section{Authors' Contributions}

Mesfin Aklilu contributed to the concept, design, data collection, analysis of the research, and manuscript write up. Waleleng Warku analyzed the data and reviewed the manuscript. Wogayehu Tadele contributed to the data collection of the research. Yimer Mulugeta and Amelework Alemu contributed to the data collection of the research. Hussene Usman, Sintayehu Abdela, and Endalkachew Birhanu entered the data into the computer. Alemnesh Hailemariam revised the manuscript.

\section{Acknowledgments}

The authors would like to express their deepest gratitude to Addis Continental Institute of Public Health for the unreserved guidance to this study. Our special thanks also go to all health workers who participated in the study.

\section{References}

[1] H. Banteyerga, M. Tharaney, and D. R. Hotchkiss, "Job satisfaction and motivation among public sector health workers: evidence from Ethiopia," Human Resources for Health, vol. 13, 2015.

[2] H. Hasanzadeh, M. B. Pashaie, A. A. Ghods, and A. Emadi, "Studying the factors affecting job satisfaction of employees of Semnan health centers," Journal of Paramedical Sciences, vol. 6, 2015.

[3] A. Y. Leja Hamza, A. Hassen, C. Jira, and M. Sudhakar, "Job satisfaction and its determinants among health workers in Jimma university specialized hospital," Ethiopian Journal of Health Sciences, vol. 21, 2011.

[4] T. Belachew, A. Asegid, and E. Yimam, "factors influencing job satisfaction and anticipated turnover among nurses in Sidama Zone Public Health Facilities, South Ethiopia," Nursing Research and Practice, vol. 2014, Article ID 909768, 26 pages, 2014.

[5] S. Santana and J. Cerdeira, "Job satisfaction among the professionals of AceS Baixo Vouga II," Acta Médica Portuguesa, vol. 24, no. 2, pp. 589-600, 2011.

[6] E. T. Bekru, A. Cherie, and A. A. Anjulo, "Job satisfaction and determinant factors among midwives working at health facilities in Addis Ababa city, Ethiopia," PLoS One, vol. 12, no. 2, Article ID e0172397, 2017.

[7] A. Yami, L. Hamza, A. Hassen, C. Jira, and M. Sudhakar, "Job satisfaction and its determinants among health workers in Jimma university specialized hospital, Southwest Ethiopia," Ethiopian Journal of Health Sciences, vol. 21, no. 1, pp. 19-27, 2011.

[8] A. Geleto, N. Baraki, G. E. Atomsa, and Y. Dessie, "Job satisfaction and associated factors among health care providers at public health institutions in Harari region, Eastern Ethiopia: a cross-sectional study," BMC Research Notes, vol. 8, no. 1, 2015.

[9] B. K. Deriba, S. O. Sinke, B. M. Ereso, and A. S. Badacho, "Health professionals' job satisfaction and associated factors at public health centers in West Ethiopia," Human Resources for Health, vol. 15, no. 1, 2017.

[10] F. C. Lunenburg, "Motivating by enriching jobs to make them more interesting and challenging," International Journal of Management, Business, and Administration, vol. 15, 2011. 
[11] N. Vawda and R. Steyn, "Job characteristics: their relationship to job satisfaction, stress and depression," Journal of Psychology in Africa, vol. 24, 2014.

[12] M. P. Nnamseh and I. A. Ayandele, "Hackman and Oldham job characteristics model (JCM) and Akwa Ibom state Civil Servants' performance," Canadian Social Science, vol. 10, no. 2, pp. 89-97, 2014.

[13] M. Antony Oladoyin, S. J. Ayamolowo, and O. Irinoye, "Job satisfaction and work environment of primary health care nurses in Ekiti state, Nigeria: an exploratory study," International Journal of Caring Sciences, vol. 6, no. 3, 2013.

[14] D. Hofoss, U. Krogstad, M. Veenstra, and P. Hjortdah, "Predictors of job satisfaction among doctors, nurses and auxiliaries in Norwegian hospitals: relevance for micro unit culture," Human Resources for Health, vol. 4, 2006.

[15] H.-O. Rashid, S. Khamlub, M. A. B. Sarker, T. Hirosawa, P. Outavong, and J. Sakamoto, "Job satisfaction of healt care workers at health centers in vientiane capital and Bolkhamsai province, LAO PRD," Nagoya Journal of Medical Science, vol. 75, 2013.

[16] K. G. MichaelMarx, I. Marx, M. Brodowski et al., "Working atmosphere and job satisfaction of health care staff in Kenya: an exploratory study," BioMed Research International, vol. 2015, Article ID 256205, 7 pages, 2015.

[17] B. O. Mokuolu and S. O. Olatunji, "The influence of sex, marital status, and tenure of service on job stress, and job satisfaction of health workers in a Nigerian Federal Health Institution," African Research Review, vol. 8, no. 1, 2014.

[18] N. Fatima, S. Younis Akhwand, M. Suleman, and M. Ibrahim, "Effect of gender differences on job satisfaction of the female employees in Pakistan," International Journal of Economics, Finance and Management Sciences, vol. 3, no. 1, p. 27, 2015.

[19] S. A. M. Ali, N. A. Said, N. a. M. Yunus, S. F. A. Kader, D. S. A. Latif, and R. Munap, "Hackman and oldham's job characteristics model to job satisfaction," Procedia-Social and Behavioral Sciences, vol. 129, pp. 46-52, 2014.

[20] H. A. Bahalkani, R. Kumar, A. R. Lakho, B. Mahar, S. B. Mazhar, and A. Majeed, "Job satisfaction in nurses working in tertiary level health care settings of Islamabad, Pakistan," Journal of Ayub Medical College, Abbottabad, vol. 23, no. 3, pp. 130-133, 2011.

[21] S. Khamlub, M. Harun-Or-Rashid, M. A. Sarker, T. Hirosawa, P. outavong, and J. Sakamoto, "Job satisfaction of health-care workers at health centers in vientiane capital and bolikhamsai province, LAO PDR," Nagoya Journal of Medical Science, vol. 75, no. 3-4, pp. 233-241, 2013.

[22] A. Tansel and S.. Gazioglu, "Job satisfaction in Britain: individual and job related factors," Applied Economics, vol. 38, 2006.

[23] Y. Lu, X.-M. Hu, X.-L. Huang et al., "Job satisfaction and associated factors among healthcare staff: a cross-sectional study in Guangdong Province, China," BMJ Open, vol. 6, no. 7, Article ID e011388, 2016.

[24] T. Dagne, W. Beyene, and N. Berhanu, "Motivation and factors affecting it among health professionals in the public hospitals, Central Ethiopia," Ethiopian Journal of Health Sciences, vol. 25, no. 3, pp. 231-242, 2015. 